\title{
What We Think Today on the Interpretation of Dreams, Forgotten and Double Senses
}

\author{
Juan Rodado1, Maria J. Rodado ${ }^{2}$ \\ ${ }^{1}$ Reina Sofia General University Hospital, University of Murcia, Murcia, Spain \\ ${ }^{2}$ Mental Health Unit, Murcia Health Service, Murcia, Spain \\ Email: jvrodado9@hotmail.com, jvrodado@um.es
}

How to cite this paper: Rodado, J., \& Rodado, M. J. (2018). What We Think Today on the Interpretation of Dreams, Forgotten and Double Senses. Psychology, 9, 773-784.

https://doi.org/10.4236/psych.2018.94049

Received: March 17, 2018

Accepted: April 21, 2018

Published: April 24, 2018

Copyright (c) 2018 by authors and Scientific Research Publishing Inc. This work is licensed under the Creative Commons Attribution International License (CC BY 4.0).

http://creativecommons.org/licenses/by/4.0/

\begin{abstract}
There are more than a hundred years since the publication of Sigmund Freud's work "the interpretation of dreams". How can we take today the ideas that Freud exposes in that text? What can we think of the interpretation of dreams, forgetfulness and double meanings? That is, the ways in which the unconscious is present in the discourse. The following work summarizes the Freudian idea about the storage of memory and about dreams and their rereading in the light of current findings in neuroscience about implicit memory, the re-consolidation of labile memories and the sleep activity that they validate in part and modify Freudian ideas in another.
\end{abstract}

\section{Keywords}

Psychoanalysis, Neuroscience, Memory, Subjectivity

\section{Interpretation of Dreams}

There are more than a hundred years since the publication of Sigmund Freud's work "the interpretation of dreams". What can we think of the work of interpreting dreams, forgetfulness and double meanings, which is how the unconscious becomes present in our discourse?

On the one hand, we would like to highlight the radical importance of this text within Freud's work and the historical context in which it is framed. Freud started from the observation of hysterical phenomena and this led him to think about the importance of child sexual life, a true taboo in that time. After publishing his first works and when it seems that his theories are admitted by the medical and university elite from the Vienna of the late 19th Century, to which Freud himself wished to ascribe himself, he writes the "Interpretation of dreams". In this text, he goes a step further by dealing with something so appar- 
ently remote from medical interest as are dreams and the analysis of their content.

On the other hand, many years have passed and we think that there is a need for a reflexive-critical view regarding a theory that can, in Castoriadis ${ }^{1}$ idea, give light to new considerations so that the truth of a thought does not succumb in the silence of what is simply ideal. In this sense, that of falling into an ideal, Ricardo Rodulfo (2013: p. 11) wonders if the psychoanalytic attitude that was once prior to the theoretical closure is recoverable. Attitude that he finds precisely in the first Freudian texts dedicated to dreams, jokes, lapses and double meanings, understanding by psychoanalytic attitude an interrogative attitude ${ }^{2}$.

Freud in "The interpretation of Dreams" prioritized the search for a latent content repressed behind the dream; this linear determinism is emerging from the paradigm of an era. Indeed, Freud conceives fantasy and the act of fantasizing as unconscious combinations of things lived and heard. From this same perspective, the dream is limited to the work of transformation (condensation and displacement) of a material that comes in some way from what is experienced. The dream is reproduced, remembered, giving rise to more complex representations of a symbolic nature.

The dream is to Freud the royal road towards the unconscious ${ }^{3}$. That area really discovered and explored by him, and that explains as follows: "we will call unconscious those latent representations of which we have some basis to suspect that they are contained in the psychic life ..." (SE 12, pp. 255). In the same work, later, Freud deepens affirming "an unconscious representation will then be a representation that we do not perceive but whose existence we are, however, soon to affirm, based on evidence and evidence" (SE 12, pp. 255).

Starting from the clinical fact of the resistance shown by his patients to raise awareness of certain representative contents of those who had no idea, Freud (1915) explains how our daily experience shows us occurrences whose origin we do not know and also results from mental processes whose elaboration we ignore. For the author all conscious acts will be meaningless if we maintain the theory that our conscience must know the totality of our psychic acts. However those conscious acts will be arranged within a coherent whole if we interpolate between them the unconscious deduced acts.

Freud is capturing the strange characteristics presented by the contents of that hidden system, a sort of ghostly scenario (the other scene in opposition to the conscious scene). Freud (1915) pointed out how says Psychoanalysis reveals to

${ }^{1}$ Castoriadis (2004: p. 281) considers that the liberation of thought, the creation of autonomous thought, of philosophy goes hand in hand with the creation of new norms of thought; in particular, for example, with the creation of this norm: I do not necessarily think what the ancients, the ancestors, the relatives or the Book, the priests or the leaders say, but I wonder what I should think... which is already a norm. And the issue does not stop there. It also refers to the content. Begin to establish new rules of inference; rigorous correspondence, verification or refutation rules, etc.

${ }^{2}$ Rodado (2016: p. 184) notes that psychoanalysis has, or must have, the subversive function of constantly questioning given patterns, so that thinking is not repetition.

3 Freud points out the following: "The interpretation of the dream is the royal road to a knowledge of unconscious activities of the mind" (SE 5, pp. 604). 
us that the essence of the repression process is not to suppress and destroy an idea that represents the drive but to prevent its access to consciousness.

It is in chapter VII of The Interpretation of Dreams (ES 5, p. 539, 540 and 543) when the first scheme of the psychic apparatus appears and the three systems that make up the first topic: the conscious, the preconscious and the unconscious.

In Figure 1, it takes the model of the reflex arc, with a sensory end that receives perceptions but lacks memory and a motor end that controls motility. There is direction with a progrediente character; the psychic processes go from the sensorial end to the motor.

Of the perceptions that we receive there remains a trace. This trace, a permanent alteration, is called the Mnemic imprint, whose function is memory and is the basis of association, that is, the possibility of interrelating all those mnemic imprints.

In this way the new aspect of the scheme is shown in Figure 2.

Another important characteristic of the $\mathrm{P}$ system is that of providing consciousness with the diversity of the sensory qualities, while our memories, when they become conscious, do not show that quality. Think of the difference between what we feel when we are burning a hand and when we remember the fact.

The mnemic imprints are grouped and, those that are furthest from consciousness, constitute the unconscious system, which has the particularity of not having access to consciousness "if it is not via the preconscious". This system, the preconscious, is located at the motor end. This is because it includes the criticizing instance that, in the dream, prevents the conscious becoming of the

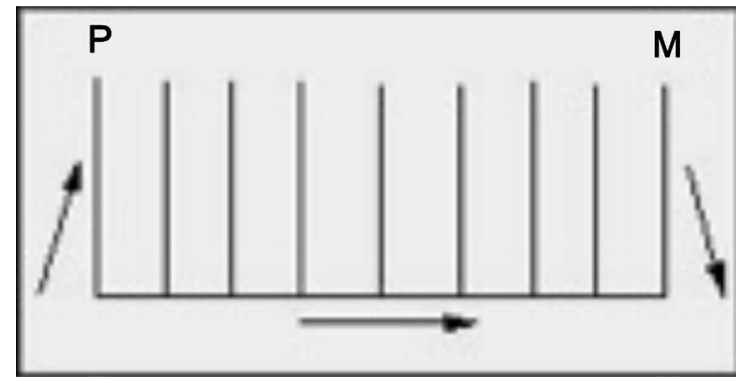

Figure 1. P: a sensory end that receives perceptions; M: a motor end that control motility.

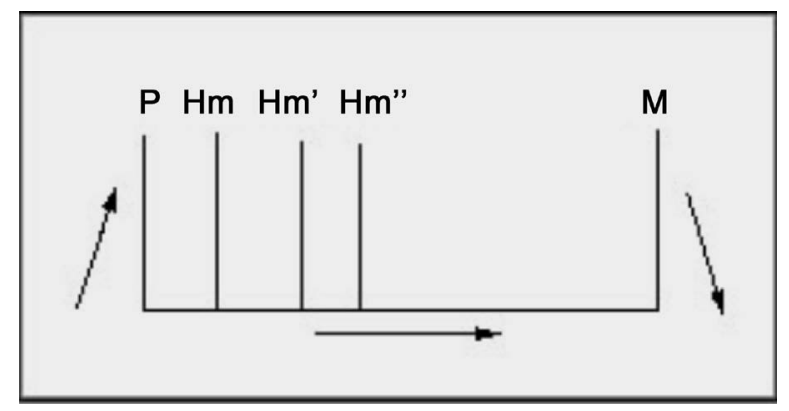

Figure 2. P: a sensory end that receives perception; Hm, Hm', Hm”: successive Mnemic imprint; M: a motor end that controls motility. 
processes activated in the unconscious and that, in the wake, possesses the key of the voluntary motility.

So, what process occurs in this psychic apparatus so that in the hallucinatory dream the unconscious representations have that sensory quality of the extreme $\mathrm{P}$ ? Freud tells us that excitement takes "a path of reflux". Instead of propagating to the motor end, through the preconscious, it takes the path of the sensory end reaching the $\mathrm{P}$ system. This directionality has a regredient character, as opposed to the progredient (see Figure 3). The author calls Regression to the phenomenon "that in the dream the representation changes again in the sensorial image from which it once departed". Regressions are also the hallucinations of hysteria and paranoia and the visions of normal people. They are "thoughts molded in images" ${ }^{\prime}$, in particular thoughts that are linked with memories that have suffocated or that have remained unconscious.

From this first scheme of psychic apparatus, which has been called First Topical, Freud is realizing daily phenomena, not those he found in the clinic, subjected also to repression. Thus the forgetfulness, the lapses of language, the joke, are formations in which Freud sees the emergence of the repressed and the effect of repression. He asks himself why they appear and after a process of analytic interrogation following the associations of mental representations, he finds the same mechanisms of deformation (condensation and displacement) as in the dream work, or in the formation of neurotic symptoms.

What is the model of memory that Freud has in his head?. From the Project (1895) appears the idea of differentiating perception of memory. The baby after

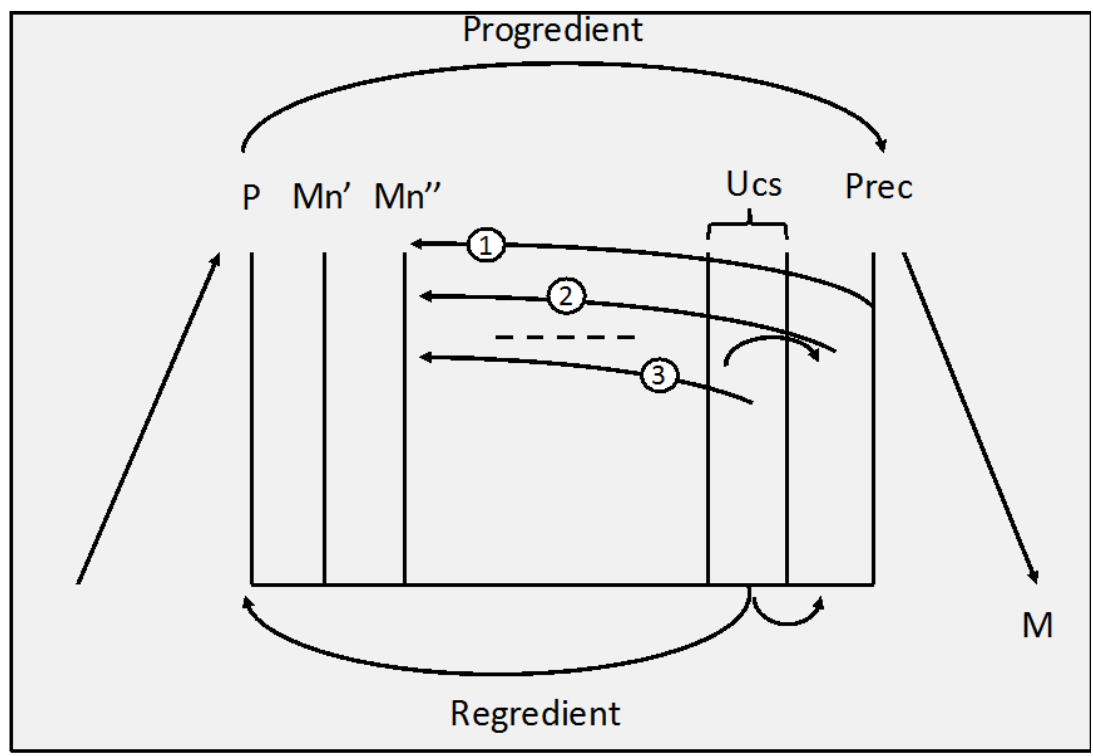

Figure 3. P: a sensory end that receives perception; Mn', Mn": successive Mnemic imprint; Ucs: unconscious system; Prec: preconscious; M: a motor end that controls motility.

${ }^{4}$ Dentico, Leung et al. (2014) conclude that "when we imagine our brain activity flows in the opposite direction to when we perceive", which is the same as saying that something similar happens when we dream or when we hallucinate. 
the experience of satisfaction hallucinates with the chest. And when he has tension again he has two options. The baby can load the mnemic imprint, that is, remember the experience of lived satisfaction which is faster but economically poorer (there is no real experience) or he can wait and perceive on the outside the object of satisfaction to be able to unload on it (to take the breast again). The way to differentiate perception and memory Freud calls it reality test. To guide oneself to this object of satisfaction, one has to load the mnemic imprint, therefore the human being is impelled to remember.

But the storage of memories is for Freud another enigma, and he treats it in "A note on the magic board" (1925). Freud asks that if each perception is stored, as when writing on a sheet of paper, the capacity to store would be finite, or we would need an "unlimited psychic surface". On the other hand, the advantage of obtaining a lasting imprint may not be so if what remains recorded as a memory loses importance or interest for the person and he no longer wishes to keep it in memory. But if, in the manner of a blackboard, the subsequent perceptive traces could be erased or written on, we could inscribe multiple memories. But to give entry to them we would have to delate the previous ones. Therefore, infinite capacity of reception and conservation of lasting imprints seem to be excluded. Freud finds in the magic blackboard, a very fashionable children's toy for those years in England (1924), a metaphor of how the psychic apparatus could inscribe the perceptions and store the mnemic imprints. And for this the scheme that appears already in chapter VII of the Interpretation of Dreams "already in the interpretation of dreams formulates the conjecture that this unusual capacity should be attributed to the operation of two different systems" (SE 5, p. 244).

The magic blackboard is a wax tablet and on it two sheets, one of paper and the other of celluloid. To use it, signs are drawn on the celluloid sheet with a punch. This in the places it touches causes the lower surface of the waxed paper to press the wax tablet and the letters appear. If you want to destroy the writing, you just have to separate the sheet from the wax tablet with a slight movement. Thus the intimate contact with the wax stops in the torn places ceases and it does not return to settle when both (sheet and tablet) are touched again. Now the blackboard has been free of all writing and ready to receive new records. But in the wax tablet retains the lasting imprint of the writing, readable with adequate lighting. The stratum receptor of stimuli does not form a lasting imprint. The foundations of memory take place in other contiguous systems. Freud makes an analogy of celluloid sheets and paper with the preconscious-conscious system, while the wax tablet would be the unconscious.

Returning to Freud's text "The interpretation of dreams", we highlight the contributions of the author that allowed psychoanalysis to become a method of understanding the psyche of any subject and not just the pathological. Freud gave the phenomenon of dreams a psychological value. The dream will be inscribed in its concepts of drive and discharge. That is to say, as a process of unloading drive stimuli whose background must be sought in the world of the 
fulfillment of infantile desires. The basic idea that Freudian theory holds is the idea of the dream as the realization of unconscious desires. This conception also conditions the role that Freud gives to the diurnal remains in the formation of the dream. While these remains help to cause the dreams, they can not form it on their own. It is always necessary to connect these with unconscious desires.

Freud (1900) recognized the difficulties in applying his unique theory of dreams in dreams of anguish. And he will offer different explanations for such inconveniences. One explanation is that this kind of dreams would be the representation of an anguish of sexual content. Another explanation is the existence of repressed desires that are not tolerated in the conscience and that when expressed cause displeasure. He also alludes to the masochistic component that arises from transforming the aggressive sadistic components in order to explain negative dreams of desires.

In this way, Freud expanded the concepts of desire and satisfaction to theoretically explain those dreams of self-punishment (ways of satisfying the superego) and dreams of anguish.

We could affirm that the only exception to the proposal of the dream as the realization of unconscious desires appears when explaining the traumatic dreams in Beyond the Pleasure Principle (Freud, 1920). However, this did not change Freud's theory of dreams, although it alters the function that the author grants to dreams. That is to say, that double function of preserving sleep according to the ego and of preserving a certain satisfaction to a repressed impulse through a hallucinatory fulfillment of desire.

Nowadays, with the discoveries of the neurosciences and the new contributions of psychoanalysis (the heterogeneity of the unconscious, the motivational systems, the writings on the intersubjectivity...) it is necessary a rethinking and revision of the texts of Freud that allow to solve the theoretical problems when we face the clinic.

In this article, taking into account the contributions of neuroscience and the knowledge of types of memory, we consider what we can add to Freud's expositions.

\section{Neuroscience and Psychoanalysis}

The current advances in neuroscience have provided us with the knowledge about psychic imprints and about memory that in some way are compatible with these theoretical speculations of Freud.

The psychic fact and the biological fact are two realities that have no comparison but that does not prevent them from being able to meet, concretely around the trace left by experience. Indeed, since the fundamental neurobiology has concretely evidenced the phenomenon of plasticity through a series of works and particularly those of Kandel, for which it won the Nobel Prize in 2000, it is possible to consider the psychic imprint as a common theme to neuroscience and psychoanalysis (Ansermet \& Magistretti, 2007). 
Thus, from the point of view of biology, the notion of imprint has become more and more precise during these last twenty years. First, there are the morphological changes induced by the impact of an experience. In addition, the experience can also modulate the efficiency of information transfer, permanently modify the synaptic transmission as revealed by the phenomenon of long-term empowerment. Already Ramón \& Cajal (1909) at the beginning of the $20^{\text {th }}$ century pointed out that the nervous connections are neither definitive nor immutable, since they are created. In other words, trial associations destined to subsist or to be destroyed according to indeterminate circumstances, a fact that demonstrates, in parentheses, the great initial mobility of the expansions of the neuron.

Freud had glimpsed the role of this plasticity in the global theory of the brain enunciated in the Project (1895). This hypothesis has been reconsidered on numerous occasions, especially by Hebb (1949), until receiving a recent experimental test, especially from the work of Kandel.

But what is this psychic imprint that we are talking about? We cannot pose things as if an experience were associated with a single trace. It is rather a set of facilitated synapses, activated in a network in the form of a set of neurons (neuronal assemblies). Hence the idea of plasticity evokes the form, as in the plastic arts. Experience gives shape; the network takes the form. Experience sculpts the neural network.

But what about the storage of those prints? What is known today with respect to memory? For some years, two types of memory have been distinguished; an explicit or conscious memory, which can be brought to the conscience verbally and a non-declarative or implicit memory that cannot be communicated verbally and in which we are going to deepen. This is the memory for those aspects of the experience that are not consciously processed and that in a didactic way we are going to divide into three:

1) Priming memory

It is the one used to remember words, sounds, shapes and sizes from fragments. It resides in presemantic perceptual centers in the sensitive cortex (the visual, auditory, tactile ... operate in different areas and separately). And is one of the headquarters of the body experiences registry

2) Procedural memory

It is the ability to store skills, habits and routines, that is, memory for skills and habits motor, perceptual and cognitive. It resides in the ganglia of the base. In amnesic patients this memory remains.

3) Emotional memory

It is the conditioned learning of emotional responses mediated by the amygdala. Activation of the amygdala causes changes in the autonomic nervous system (heart rate, gastric motility and vasodilation). These changes are stored elsewhere than the factual details of the event.

In the early stages of development, explicit memory is scarce due to the immaturity of the cortical connections of the hippocampus. However the implicit 
memory is well developed because the ganglia of the base and the amygdala are. They sustain the existence of the implicit memory of unconscious infantile experiences, fears, somatic symptoms, patterns of interaction (including the mother-baby relationship).

In the body, memories of bodily experiences without semantic correlation are imprinted because they could not be consolidated in a hippocampus insufficiently connected with the cortex (an example "the ghost member").

Towards the end of the 1960s, the dominant vision of the storage dynamics of memory, in which it progresses unfailingly towards a state of progressive stabilization, begins to be challenged by the results of different works. So Misanin (1968) presents animals with a previously consolidated memory an experience related to the original learning, (a reminder of training). After the experiment he found that there was a return of this memory to the labile state. In this re-labilization, the memory must go through a new period of consolidation, or reconsolidation, in order to remain again in the long term.

There is a series of molecular events that occur in synapses, and that also involve the nuclei of these neurons, at the time of the formation and consolidation of memory. Some of these described events involve different membrane receptors, calcium-mediated signaling, cAMP, cascades of kinases and activation of transcription factors, culminating in the expression of different genes.

The main theoretical objection to the hypothesis of the reconsolidation resides in the disconcerting biological sense and adaptive value of the return of a consolidated memory to the labile state.

With her work, Sara (2000), Sara \& Hars (2006) showed in different models of memory with appetitive and adverse rodents that the presentation of a reminder weakened the consolidated memory. And that the memory could be prevented after its labilization by the administration of specific antagonists of NMDA receptors and beta-adrenergic receptor antagonists.

An unstimulated stimulus (CS) could have the capacity to induce the phenomenon of reconsolidation of the old memory by constituting a related experience but with new information (of different sign) with respect to previous learning. On the other hand, a reinforced CS, that constitutes an experience in which the ratio of stimuli is the same as in training, will have the ability to induce this phenomenon of reconsolidation. This occurs if the reinforced stimulus has the intensity necessary to induce long-term plasticity phenomena. This described experience would probably represent a significant episode in relation to the original learning.

There is an adaptive value in the phenomenon of memory reconsolidation: when the memory is labilized by some related stimulus, the memory will be susceptible to the action of modulators or other endogenous agents. The old memory can acquire a new meaning value, depending on the new context cognitive in which it was labilized.

This theory of reconsolidation is not far from the idea of resignification that 
Freud took to think about repression and the formation of the repressed unconscious. There are experiences that resignify a previous experience.

\section{The Human Subjectivity}

Despite the criticism received from the environment of the philosophy of science, in particular from Grunbaum (1993) on the non-demonstrability of psychoanalytic hypotheses, Kandel (1999) says that psychoanalysis still represents the most coherent and intellectually perspective of the mind.

What could we say today about the interpretation of dreams? Are dreams, forgetfulness and lapses important in the way we approach the clinic and treat human suffering? Which do they represent?

According to knowledge of implicit memory, we know that there is a part of human experiences, which are stored without being able to be told verbally. We refer to the most significant experiences, that is, those that occur in the time of greatest psychic distress due to brain immaturity and therefore the greatest need for help from another human being. Sensory experiences, the mother-baby dyad with all its relational qualities, the modes of attachment, "internal models working" described by Bowlby (1988) would form part of the content of that implicit, unconscious memory, although it does not correspond to the dynamic unconscious of Freud.

The unconscious memory is continually put into play in our way of relating. Current psychoanalyst such as Bollas (1991) calls this content, the known not thought and say that forms the personal language of each subject. The evolutionary psychologist and psychoanalyst Stern (1985) calls it implicit relational knowledge and says it is activated every time we interact with someone.

But how to analyze this content and what does it have to do with dreams, if it cannot be brought verbally? In the analysis of dreams what we use are precisely the words. What influence do all these experiences have on the content of dreams, in the act of dreaming?

Neurobiology has shown that sleep as we know it, with its oddities and improbable syntax, depends on a certain phase, the paradoxical dream, which is inscribed in the overall architecture of the dream.

Contrary to the Freudian idea of the dream as hallucinatory satisfaction of desires, it is known that the dream comes from a rhythm in which the slow phase and the paradoxical phase alternate, independently of any realization of desire. In other words, it is not desire that originates the dream as a hallucinatory realization since it occurs at regular intervals that have nothing to do with the staging of desire. In effect, desire can participate in the dream process without it being its primum movens. In addition, it is important to note that dream activity also appears during slow sleep, closer to real events, unlike what happens during the paradoxical dream in which deformations occur and symbolic contents appear. In this way, we do not stop dreaming throughout the night, just as we do not stop thinking about the waking state (not thinking is also thinking!). 
The dream is no longer just a hallucinatory expression of desire, what is the dream? Answering this question we bring a small and magnificent text by Susana Rotbard (2000) written with the French psychoanalyst of Egyptian origin Sa$\mathrm{mi}$ Ali. The text is entitled "dream and affection 100 years later" and it deals with the important question of the imaginary. For both authors, the imaginary has a fundamental value: as a function that is constituted in its lower limit from the body as a representation scheme. This is the body in its original projection power that determines in man a representative and affective incessant flow-the imagination and promotes the representation of oneself and of reality. In the upper limit, the imaginary is constituted from the mother tongue which is equivalent to saying within an affective relationship "sense and sound matrix".

The imaginary constructs subjective space and time. We see that the projection as a subjective function that determines the discovery-creation of the world, simultaneously transforms into the discovery-creation of the subject. This dialectic comprises the construction of the space of reciprocal inclusions that symbolically equates the outside to the inside relying on each other in a circular continuity that characterizes the affective experience. Thanks to this experience we find on the outside what is inside the subject and at the same time, the subject apprehends from the outside what is inside.

Both authors reject the body mind duality. The dream would no longer be, as Freud sees it, a product of a psychic apparatus, but is inserted in a bodily production, in a rhythm that directs all psychosomatic functioning. And it is constituted around the oscillation between vigil consciousness and dream consciousness. Oscillation that establishes a double relation of inclusion and exclusion between the two consciousness allowing to distinguish new ways of functioning that are the basis of any concrete description of the clinical phenomenon. Phenomenon that is defined only in relation to the dream and the place it occupies in the global functioning of the subject. And by dream we must understand not only the nocturnal event but also its equivalent in the wake; fantasy, illusion, magical behavior, transference, hallucination, play, etc., without forgetting the affect whose problematic can only be approached through this genealogy of the imaginary.

Somehow the child loses something by having to code verbal preverbal experiences with the acquisition of language. Stern (1985) points out that the period around a year and a half is particularly difficult for the child because the pre-verbal experiences are re-encoded verbally. However, this new coding covers only a part of the lived pre-verbal experience, since certain experiences cannot be captured in the language network. If a yellow light was until then the sum of sensations of heat, color and feelings provoked by that light, with the introduction of language the word "yellow" accentuates the visual aspect of that totality, which makes the sensation of heat, for example, get lost or go to the background. The original totality of the lived experience is broken, which provokes a crisis in the understanding and in the feeling of oneself that the child has (Stern, 1985: p. 
247). It is for this reason that this period becomes difficult for him.

These preverbal experiences are those found in artistic creation, in music, in poetry, in children's games. And in our opinion they are the ones that constitute the material of dreams, the material of what Freud called primary process, the unconscious, and that are part of that oneiric consciousness of which Sami-Ali and Susana Rotbard speak. In front of this type of consciousness, an excessive subordination to the vigil consciousness (to the secondary process) gives rise to the repression of the imaginary, to the loss of the ability to play and ultimately to the loss of the ability to dream.

Therefore, what are dreams? How to interpret them ? Dreams are, along with play, creation and illusion, direct expression of subjectivity, the core of the human being. Subjectivity that is at the center of the research that Freud began at the end of the 19th century. And that at present it can continue as a theory of the mind and as a psychotherapeutic approach whenever we take into account the current findings of cognitive neuroscience (Barret, 2002; Hobson et al., 2000).

In the article and with the mention of some of the neuroscientific advances on the biological bases and types of memory, we invite a reconceptualization that has implications in the analysis of dreams and in the process of therapeutic change as Bleichmar (2001) describes. We introduce the bipersonal dimension and how the dream is inscribed in the analyst-patient encounter. The mentioned studies on the reconsolidation of Sara's memory are an opportunity to think about psychotherapeutic interventions that make it possible to relax memories of traumatic events and change their significance. Therefore, the analysis of dreams as an experiential element in the transference-countertransference interplay can contribute to new ways of relating to the other and modifying procedural memory (Bleichmar, 2001). These advances also force us to consider a broad view of the unconscious that contemplates its heterogeneity and not only the repressed unconscious as it appears in Freud's text "The interpretation of dreams".

However, despite these contributions of our work, we are critical of our general perspective. And we considered that it would be necessary to add in the analysis of the dreams the specificities linked to the particularities of the functioning of each one of the patients, which would determine a more focused treatment. In addition this work could be completed with the contributions of Fonagy (2000) on mentalization in the analysis of dreams.

\section{References}

Ansermet \& Magistretti (2007). A cada cual su cerebro [To Each His Brain]. Buenos Aires: Katz Ed.

Barret, D. (2002). The "Royal Road" Becomes a Shrewd Shortcut. Journal of Cognitive Psychotherapy, 16, 55-63. https://doi.org/10.1891/jcop.16.1.55.63701

Bleichmar, H. (2001). El cambio terapéutico a la luz de los conocimientos actuales sobre la memoria y los múltiples procesamientos inconscientes (The Therapeutic Change in Light of Current Knowledge about Memory and the Multiple Unconscious Processes). 
Aperturas psicoanáliticas, 9. http://www.aperturas.org/

Bollas, C. (1991). La sombra del objeto. Psicoanálisis de lo sabido [The Shadow of the Object: Psychoanalysis of the Unthought Known]. Buenos Aires: Amorrortu ed. (Published in English by Columbia University Press, 1987)

Bowlby, J. (1988). Una Base segura. Aplicaciones clínicas de una teoría del apego [A Secure Base. Clinical Applications of an Attachment Theory]. Buenos Aires: Paidos.

Castoriadis, C. (2004). Sujeto y verdad en el mundo histórico social [Subject and Truth in the Social Historical World]. Fondo de Cultura Economica de Argentina, Buenos Aires.

Dentico, D., Leung, B., Cheung, P., Chang, Y., Guokas, J., Boly, M., Tononi, G., \& Van Veen, B. (2014). Reversal of Cortical Information Flow during Visual Imagery as Compared to Visual Perception. NeuroImage.

https://doi.org/10.1016/j.neuroimage.2014.05.081

Fonagy, P. (2000). Dreams of Borderline Patients. In R. J. Perelberg (Ed.), Dreaming and Thinking (pp. 91-108). Karnack Books.

Freud, S. (1895). A Project for a Scientific Psychology (Standard Edition, Vol. 1, pp. 283-397). London: Hogarth.

Freud, S. (1915). The Unconscious (Standard Edition, vol. 14, pp. 159-190). London: Hogarth.

Freud, S. (1920). Beyond the Pleasure Principle (Standard Edition, Vol. 18, pp. 7-64). London: Hogarth.

Freud, S. (1925). A Note upon the "Mystic Writing-Pad" (Standard Edition, Vol. 19, p. 230). London: Hogarth.

Grunbaum, A. (1993). Validation in the Clinical Theory of Psychoanalysis. Madison, WI: International Universities Press.

Hebb, D. O. (1949). The Organization of Behavior. New York: Wiley.

Hobson, J. A., Pace-Schott, E., \& Stickgold, R. (2000). Dreaming and the Brain: Towards a Cognitive Neuroscience of Conscious States. Behavioral and Brain Sciences, 23, 793-842. https://doi.org/10.1017/S0140525X00003976

Kandel, E. (1999). Biology and the Future of Pyschoanalysis. A New Intellectual Framework for Psychiatry Revisited. The American Journal of Psychiatry, 156, 505-524.

Misanin et al. (1968). Retrograde Amnesia Produced by Electroconvulsive Shock after Reactivation of a Consolidated Memory Trace. Science, 160, 554-555.

https://doi.org/10.1126/science.160.3827.554

Ramón, \& Cajal (1909). Histology of the Nervous System of Man and Vertebrates [Histology of the Nervous System of Man and Vertebrates]. Paris: A. Maloine.

Rodado, J. (2016). What Do We Think about When We Think about Psychoanalysis. International Forum of Psychoanalysis, 25, 179-185. https://doi.org/10.1080/0803706X.2015.1020868

Rodulfo, R. (2013). Scaffolds of Psychoanalysis [Scaffolds of Psychoanalysis]. Buenos Aires: Paidos.

Rotbard, S., \& Ali, S. (2000). El sueño y el afecto, cien años después Actualidad Psicológica no 276 "La interpretación de los sueños". Buenos Aires: República Argentina.

Sara, S. J. (2000). Retrieval and Reconsolidation: Howard a Neurobiology of Remembering. Learning \& Memory, 7, 73-84. https://doi.org/10.1101/lm.7.2.73

Sara, S. J., \& Hars, B. (2006). In Memory of Consolidation. Learning \& Memory, 5, 515-521. https://doi.org/10.1101/lm.338406

Stern, D. (1985). The Interpersonal World of the Infant (p. 1). New York, NY: Basic Books. 